\title{
Mechanical ventilation in trauma-the first 24 hours: A retrospective analysis
}

\author{
Rakesh Kumar', Amit Sharma ${ }^{2, *}$, U Naga Satish ${ }^{3}$ \\ ${ }^{1}$ Seinor Consultant, ${ }^{2} \mathrm{HOD}$ and Senior Advisor, ${ }^{3} \mathrm{Junior}$ Consultant, ${ }^{1}$ Dept. of Surgery, ${ }^{2,3}$ Dept. of Anaesthesia, ${ }^{\mathbf{1}}$ Northern \\ Command Medical Head Quarters, Udhampur, Jammu \& Kashmir, 2,392 Base Hospital, Srinagar, Jammu \& Kashmir, India
}

\author{
*Corresponding Author: Amit Sharma \\ Email: dramitsharms@gmail.com
}

Received: $11^{\text {th }}$ September 2018

Accepted: $20^{\text {th }}$ September 2018

\begin{abstract}
Introduction: Warfare injuries are a special subset of trauma, involving complex injury mechanisms and extensive tissue damage. Theses mechanisms may lead to significant deterioration in lung function even in the absence of any signs of external thoracic injury due to primary or secondary insult on the lungs. The mainstay in the management of these battlefield lung injuries is by initiating mechanical ventilation which either replaces or assists the functions of the respiratory system.

Materials and Methods: A retrospective analysis was done from $1^{\text {st }}$ January 2016 to $31^{\text {st }}$ June 2016 of the data taken from the trauma register of our hospital. Data was analysed and the need for mechanical ventilation was correlated with factors like injury severity score (ISS), injury profile and pulmonary and extrapulmonary using confidence interval and Odds ratio. Paired differences were tested using Wilcoxon signed rank test.

Results: Of the 528 warfare casualties received a total of 469 patients were enrolled and 94(20.04\%) required mechanical ventilation in the immediate post-operative period and another 06 patients needed ventilation in the first 24 hours due to development of fat embolism syndrome. All patients had an ISS of greater than 27(48.9 \pm 12.6$)$ as compared to non-ventilated patients (odds 1.1, 95\% CI, 0.85-1.45, $\mathrm{P}=0.42$ ).

Conclusion: Acute lung injury is a major cause of increased morbidity in patients with warfare injuries. An aggressive and proactive approach of initiating mechanical ventilation can bring down complications and ICU stays. Injury severity scoring can be used for predicting ALI in warfare casualties. Lung protective ventilatory strategies can enhance patient recovery.
\end{abstract}

Keywords: Mechanical ventilation, Trauma, Lung injury.

\section{Introduction}

Warfare injuries are a special subset of trauma, with injury mechanism involving mainly of penetrating missiles, blast waves and burns. All conventional battle injury mechanisms involve extensive tissue damage due to high energy transfer to the tissues from the injuring agent. These types of trauma lead to acute lung injury either by direct injury or indirect mechanisms. Acute lung injury is a known complication of major trauma with incidence varying from $8 \%$ to $82 \%$ in both civil and military trauma. ${ }^{1}$ The subgroup of patients having lung injury mainly comprise of pulmonary contusions, severe sepsis, severe trauma (with Injury Severity score >25), head injury, notable base deficit, massive blood transfusion requirement and severe orthopaedic injuries. ${ }^{2,3}$

Military physicians have first recognised a disease process affecting the lungs that plagued the successful treatment of wounded combatants during world war I and termed it "posttraumatic pulmonary massive collapse." " In world war II military thoracic surgeons identified that battle casualties with "wet lung" disease had poor survival rates than their counterparts with dry lungs. ${ }^{5}$ In 1967, Vietnam war has seen the resurgence of the lung effects of warfare injuries, now termed the "Da Nang lung" or "shock lung." At about the same time Ashbaugh et al have published the landmark article that coined the term ARDS (acute/adult respiratory distress syndrome) in patients with acute respiratory failure from a variety of traumatic and nontraumatic causes. $^{7}$

The mechanism of injury to the lungs in warfare trauma can be both pulmonary or extrapulmonary causes. Both mechanisms may lead to significant deterioration in lung function even in the absence of any signs of external thoracic injury. The direct pulmonary trauma is further classified as penetrating and blunt trauma. High velocity injuries to the lungs result in rapid expansion of the gas filled alveoli leading to inflammatory response which damages the alveolar-capillary barrier. Extrapulmonary insults in warfare trauma include sepsis, aspiration pneumonias, massive transfusions, and multiple trauma itself causes ARDS. It was found that lung injury can be both a consequence or a cause for multiple organ dysfunctions. ${ }^{8-10}$

The mainstay in the management of these battlefield lung injuries is by initiating mechanical ventilation which either replaces or assists the functions of the respiratory system. Mechanical ventilation acts like a double-edged sword which might exacerbate the initial injury by direct mechanical injury, surfactant failure, stimulation of inflammatory mediators both systemic and pulmonary. ${ }^{11}$ The better understanding of the mechanisms of injuries and pathophysiology of ARDS has led to development of safer ventilation strategies and better outcomes. This study outlines our experiences in acute respiratory failure following 
conventional warfare injuries and their outcomes based on ventilatory strategies. Statistical results are aimed comparing the pulmonary and extrapulmonary aetiologies leading to mechanical ventilation. An attempt was made to correlate the severity of injury based on Injury Severity Score (ISS) and the need for mechanical ventilation.

\section{Materials and Methods}

After attaining the institutional ethical committee approval, all patients who sustained warfare related injuries namely gunshot wounds, grenade or mine blast injuries and projectile injuries received in our trauma centre between 01 January 2016 to 31 June 2017 were enrolled into the study. A retrospective, case control study was devised and data was collected from the trauma registry of our hospital. Warfare casualties are evacuated to our hospital either directly from the field or after initial resuscitation in the field ambulance. Patients who were declared dead or evacuated to a higher centre within the first 24 hours were excluded from the study. Patients with isolated head injury as evidenced by clinical examination and radiological investigation were excluded from the study. Patients with incomplete data available were also excluded from the study.

A total of 528 casualties were received in our trauma centre within the study duration and of which 469 patients were enrolled into the study. The injury severity score (ISS) was calculated with the help of online ISS calculator www.trauma.org/archive/score/isscalc.html.

Mechanical ventilation was initiated in patients with the following indications. ${ }^{12}$

1. Pulmonary contusions with respiratory distress and arterial blood gas(ABG) abnormalities ( $\mathrm{PaO} 2<60$ $\mathrm{mm}$ of $\mathrm{Hg}$ or $\mathrm{PaCO} 2>60 \mathrm{~mm}$ of $\mathrm{Hg}$ )

2. Acute Respiratory Distress Syndrome.

3. Extensive abdominal trauma.

4. Airway burns.

5. Fat embolism syndrome.

6. Patients requiring massive blood transfusions.

7. Sustained hypotension postoperatively.

8. Systemic Inflammatory Response syndrome (SIRS) or sepsis.

9. Polytrauma (involving more than one major organ system).

All patients were placed on pressure controlled ventilation with low tidal volume and optimal PEEP (Positive End Expiratory Pressure). The ISS was calculated in all patients and correlated with the need for mechanical ventilation in the first 24 hours. The vital parameters mainly heart rate, blood pressure (systolic, diastolic and mean) and $\mathrm{ABG}$ parameters were analysed after 24 hours of initiation of mechanical ventilation.

\section{Statistical Analysis}

The data obtained from the trauma registry was compiled and analysed using the Windows EXCEL and XLSTAT plug-in. Descriptive analysis was done using frequencies and $95 \%$ confidence intervals (CI) for categorical variables, and mean standard \pm deviation for continuous variables. The unpaired t-test was used to compare the study variables of the two study groups. Pvalue was used to statistically signify the variations in the study parameters. A P-value $<0.01$ is considered very significant and $\mathrm{P}<0.05$ was considered statistically significant.

\section{Results}

During the 18-month study duration, a total of 528 warfare casualties were received and after careful exclusion, a total of 469 patients were enrolled into the study. All the patients were young healthy males within the age group of 20 to 52 years $(30.9 \pm 6.82$ years $)$. The mechanism of injury comprised of gunshot wounds, mine blast injuries and splinter injury due to grenade blasts and burn injuries both chemical and thermal. Of the patients received $22(4.7 \%)$ patients had face injuries, 29(6.2\%) had isolated chest injuries, $60(12.8 \%)$ sustained abdominal injuries, 104(22.1\%) had lower limb injuries, 74(15.7\%) had upper extremity injuries, $7(1.5 \%)$ patients had thermal burn injuries and $173(36.8 \%)$ patients had multiple anatomical injuries.

Of the casualties enrolled, 94(20.04\%) patients needed mechanical ventilation in the post-operative period. Another 06 patients needed instillation of mechanical ventilation after the first 24 hours. All patients were followed up with an ABG analysis after the first 24 hours. There was clinical improvement both in the vital parameters and the blood gases in the ventilated group. $64(13.6 \%)$ patients were weaned off the ventilator after first 24 hours and within 48 hours of ventilation. $30(6.4 \%)$ patients required mechanical ventilation beyond first 48 hours of ventilation.

All patients on mechanical ventilation were with an ISS greater than $27(48.9 \pm 12.6)$. Non-ventilated patients predominantly had lower ISS $(30.3 \pm 11.2)$. The ISS has a statistically better predictability for initiation of mechanical ventilation and can be used as a guide for identifying candidates that might require mechanical ventilation $(\mathrm{P}<0.001, \mathrm{CI}=95 \%)$.

Heart rate of patients on mechanical ventilation had improved within the first 24 hours maybe due to better oxygenation and controlled systemic effects. Mean heart rate after the first 24 hours was $82.5 \pm 23.3$ in the ventilated group as compared to $113.6 \pm 20.2$ beats $/ \mathrm{min}$ in the non-ventilated group which was extremely statistically significant ( $\mathrm{P}<0.001, \mathrm{CI}=95 \%)$.

There was an increased requirement of inotropic support in the ventilated patients, maybe owing to the increased severity of injury in the ventilator group. $26(27.66 \%)$ patients required low dose infusions of Noradrenaline as compared to $68(18.13 \%)$ patients in 
the non-ventilated group. The increased requirement though was statistically not significant $(\mathrm{P}=0.9)$.

The oxygenation quotient quantified by the partial pressure of oxygen has improved in the ventilated patient group with a $\mathrm{PaO} 2$ of $132.7 \pm 32.3 \mathrm{~mm}$ of $\mathrm{Hg}$ as compared to $72.4 \pm 42.6 \mathrm{~mm}$ of $\mathrm{Hg}$ in the non-ventilated group and the difference is statistically significant. $(\mathrm{P}<0.001, \mathrm{CI}=95 \%)$.

The mean duration of discharge of patients from the ICU is $147.6 \pm 27.5$ hours. The duration of patients on mechanical ventilation was higher than the nonmechanically ventilated patients with the mean durations being $182.8 \pm 38.6$ hours and $138.23 \pm 25.9$ hours respectively.

Table 1: Parametes of study

\begin{tabular}{|l|c|c|}
\hline \multicolumn{1}{|c|}{ Parameter } & Venti grp & Non venti grp \\
\hline Patients & 94 & 375 \\
\hline $\mathrm{HR}$ (mean) bpm & 82.5 & 113.6 \\
\hline $\begin{array}{l}\mathrm{PaO} 2 \text { (mean) mm of } \\
\mathrm{Hg}\end{array}$ & 132.7 & 72.4 \\
\hline Hours of stay in ICU & 182.8 & 138.2 \\
\hline
\end{tabular}

\section{Discussion}

Any type of major trauma leading to extensive tissue damage becomes a etiological factor for the development of acute lung injury (ALI) and ARDS which is associated to an increased rate of morbidity and mortality in studies across the globe. ${ }^{13,14}$ But the outcomes of patients with major trauma leading to ALI and ARDS have improved over time maybe due to the advent of better ventilatory strategies and proactive approach towards management of the complications. ${ }^{15}$

There was an increased incidence of requirement of mechanical ventilation in patients with higher ISS (ISS > 27) than with patients having lower ISS irrespective of the organ system involved. Study published by Ali Salim et al in 2006 has attributed the injury severity to higher incidence of ARDS and morbidity as compared to the control group but no increased mortality in the test group. ${ }^{16}$ Miller et al has concluded that an ISS $>25$ stands an independent risk factor for developing ARDS in trauma patients. ${ }^{13}$

The secondary objective of the study is to focus on the benefits of initiation of optimised mechanical ventilations (within the first 24 hours) in decreasing morbidity and better clinical profile in warfare trauma. There was a notable improvement in vital parameters namely heart rate and oxygenation when ventilation was initiated early in the disease process. A study conducted by Borges et al has concluded that hypoxemia can be completely reversed and lung completely recruited by intervening early in ARDS. ${ }^{17}$ It has also been postulated that the ARDS associated with trauma may be different from that caused by other aetiologies as patients may be much younger with fewer associated medical conditions. ${ }^{18}$ So early intervention can lead to a better clinical outcome and decrease the ensuing morbidity of these trauma related victims.

It was also observed that the severity of injury mandates early and safe ventilatory strategy irrespective of the site of injury stressing the extrapulmonary mechanisms involved in deranging the pulmonary function in high velocity warfare injuries.

\section{Conclusion}

Acute lung injury is a major cause of increased morbidity in patients with extensive warfare injury and an aggressive and proactive approach by instilling mechanical ventilation in such cases can bring down complications and ICU stays in such patients. Injury severity scoring can be used for predicting acute lung injury in warfare casualties. Lung protective ventilatory strategies can enhance patient recovery and early discharge from ICU.

\section{Author Contributions}

1. Col Amit Sharma: Study design, manuscript revision.

2. Maj Gen Rakesh Kumar: Patient recruitment, drafting of first paper.

3. Capt U Naga Satish: Data Collection, data analysis.

\section{Conflict of Interest: None.}

Funding: No financial grant received.

\section{References}

1. Hoyt DB, Simons RK, Winchell RJ, Cushman J, Hollingsworth-Fridlund P, Holbrook T et al. A risk analysis of pulmonary complications following major trauma. J Trauma. 1993;35(4):524-31.

2. Hudson LD, Milberg JA, Anardi D, Maunder RJ.. Clinical risks for development of the acute respiratory distress syndrome. Am J Respir Crit Care Med. 1995;151(2 Pt 1):293-301.

3. Navarrete-Navarro P, Rodriguez A, Reynolds N, West R, Habashi N, Rivera R et al. Acute respiratory distress syndrome among trauma patients: trends in ICU mortality, risk factors, complications and resource utilization. Intensive Care Med. 2001;27(7).

4. AB M. Early description of ARDS. Chest. 1991;99:2612.

5. Buford TH. Wet lung in Surgery In World War II. Thoracic surgery. 1965;2:207-36.

6. Col Morris MJ. Acute Respiratory Distress Syndrome in Combat Casualties: Military Medicine and Advances in Mechanical Ventilation. Military Medicine. 2006;171(11):1039-44.

7. Ashbaugh DG, Bigelow DB, Petty TL, Levine BE. Acute respiratory distress in adults. Lancet. 1967;2:319-23.

8. Hoff SJ, Shotts SD, Eddy VA, Morris JA Jr. Outcome of isolated pulmonary contusion in blunt trauma patients. Am Surg. 1994;60:138-42.

9. Walker ML. Trauma - adult respiratory distress syndrome. J Natl Med Assoc. 1991;83:501-4.

10. Del Sorbo L, Alutsky AS. Acute respiratory distress syndrome and multiple organ failure. Curr Opin Crit Care. 2011;17:1-6. 
11. Pinhu L, Whitehead T, Evans T, Griffiths M. Ventilatorassociated lung injury. Lancet. 2003;361:332-40.

12. Shubhangi Arora, Preet Mohinder Singh, Anjan Trikha. Ventilatory stratergies in trauma patients. $J$ Emerg Trauma Shock. 2014;7(1):25-31.

13. Miller PR, Croce MA, Kilgo PD, Scott J, Fabian TC. Acute respiratory distress syndrome in blunt trauma: identification of independent risk factors. Am Surg. 2002;68:845-50.

14. Eberhard LW, Morabito DJ, Matthay MA. Initial severity of metabolic acidosispredictsthe development of acute lung injury inseverely traumatized patients. Crit Care Med. 2000;28:125-31.

15. Rocco TR Jr, Reinert SE, Cioffi W, Harrington D, Buczko G, SimmsHH. A9-year single-institution, retrospective review of death rate and prognostic factors in adult respiratory distress syndrome. Ann Surg. 2001;233:414-22.

16. Ali Salim, Matthew Martin, Constantinos Constantinou, Burapat Sangthong, Carlos Brown, George Kasotakis, Demetrios Demetriades, Howard Belzberg. Acute Respiratory Distress Syndrome in the Trauma Intensive Care Unit. Morbid but not Mortal. Arch Surg. 2006;141:655-8.
17. Borges JB, Okamoto VN, Matos GF, Caramez MP, Arantes PR, Barros F, Souza CE, Victorino JA, Kacmarek RM, Barbas CS, Carvalho CR, Amato MB. Reversibility of lung collapse and hypoxemia in early acute respiratory distress syndrome. Am J Respir Crit Care Med. 2006;174(3):268-78.

18. Calfee CS, Eisner MD, Ware LB, Thompson BT, Parsons PE, Wheeler AP, Korpak A, Matthay MA. Acute Respiratory Distress Syndrome Network, National Heart, Lung, and Blood Institute: Trauma-associated lung injury differs clinically and biologically from acute lung injury due to other clinical disorders. Crit Care Med. 2007;35(10):2243-50.

How to cite this article: Kumar R, Sharma A, Satish U N. Mechanical ventilation in trauma-the first 24 hours: A retrospective analysis. Indian $\mathrm{J}$ Clin Anaesth. 2018;5(4):465-468. 